\title{
Prevalence and Severity of Anaemia Stratified by Age and Gender in Rural India
}

\author{
Gerardo Alvarez-Uria, Praveen K. Naik, Manoranjan Midde, \\ Pradeep S. Yalla, and Raghavakalyan Pakam \\ Department of Infectious Diseases, Bathalapalli Rural Development Trust Hospital, Kadiri Road, Bathalapalli,
Anantapur District, Andhra Pradesh 515661, India
}

Correspondence should be addressed to Gerardo Alvarez-Uria; gerardouria@gmail.com

Received 22 September 2014; Accepted 21 November 2014; Published 4 December 2014

Academic Editor: Aurelio Maggio

Copyright (C) 2014 Gerardo Alvarez-Uria et al. This is an open access article distributed under the Creative Commons Attribution License, which permits unrestricted use, distribution, and reproduction in any medium, provided the original work is properly cited.

\begin{abstract}
Anaemia is a major public health problem in India. Although nearly three quarters of the Indian population live in rural areas, the epidemiology of anaemia in rural settings is not well known. We performed a retrospective observational study using routine clinical data from patients attending the out-patient clinics of a rural hospital in India from June 2011 to August 2014. The study included 73,795 determinations of haemoglobin. $49.5 \%$ of patients were female. The median haemoglobin concentration was $11.3 \mathrm{~g} / \mathrm{dL}$ (interquartile range (IQR), 9.8-12.4) in females and $12.5 \mathrm{~g} / \mathrm{dL}$ (IQR, 10.6-14.2) in males. Anaemia was present in the majority of children $<10$ years, women after puberty, and older adults. Children $<5$ years had the highest prevalence of anaemia, especially children aged 1-2 years. The high proportion of microcytic anaemia and the fact that gender differences were only seen after the menarche period in women suggest that iron deficiency was the main cause of anaemia. However, the prevalence of normocytic anaemia increased with age. The results of this study can be used by public health programmes to design target interventions aimed at reducing the huge burden of anaemia in India. Further studies are needed to clarify the aetiology of anaemia among older adults.
\end{abstract}

\section{Introduction}

According to the World Health Organization (WHO), there are two billion people with anaemia in the world and half of the anaemia is due to iron deficiency [1]. Anaemia is a late indicator of iron deficiency, so it is estimated that the prevalence of iron deficiency is 2.5 times that of anaemia $[1,2]$. The estimated prevalence of anaemia in developing countries is $39 \%$ in children $<5$ years, $48 \%$ in children $5-$ 14 years, $42 \%$ in women $15-59$ years, $30 \%$ in men $15-59$ years, and $45 \%$ in adults $>60$ years [1]. These staggering figures have important economic and health consequences for low- and middle-income countries. Anaemia and iron deficiency lead to substantial physical productivity losses in adults [2]. Iron deficiency during pregnancy is associated with maternal mortality, preterm labour, low birth-weight, and infant mortality [2]. In children, iron deficiency affects cognitive and motor development and increases susceptibility to infections [3].
Anaemia is a major health problem in India. In the 20052006 National Family Health Survey (NFHS-3), a household survey aimed at having national and state representative data on population health and nutrition; the prevalence of anaemia was $70 \%$ in children aged $6-59$ months, $55 \%$ in females aged $15-49$ years, and $24 \%$ in males aged $15-49$ years [4]. Although the NFHS-3 showed that the prevalence of anaemia was higher in rural areas, there is a paucity of data about the epidemiology of anaemia in rural settings [5]. The aim of this study is to describe the prevalence of anaemia among patients who attended the outpatient clinics of a rural hospital in Andhra Pradesh, India.

\section{Methods}

2.1. Setting. The study was performed in Anantapur, a district situated in the South border of Andhra Pradesh, India. Anantapur has a population of approximately four million 
TABLE 1: Haemoglobin concentrations ( $\mathrm{g} / \mathrm{dL}$ ) for the diagnosis of anaemia and assessment of severity according to the World Health Organization.

\begin{tabular}{lccc}
\hline Age & Mild & Moderate & Severe \\
\hline 6-59 months & $10-10.9$ & $7-9.9$ & $<7$ \\
5-11 years & $11-11.4$ & $8-10.9$ & $<8$ \\
12-14 years & $11-11.9$ & $8-10.9$ & $<8$ \\
Female $>14$ years & $11-11.9$ & $8-10.9$ & $<8$ \\
Male $>14$ years & $11-12.9$ & $8-10.9$ & $<8$ \\
\hline
\end{tabular}

people. In Anantapur, $72 \%$ of the population live in rural areas and $36 \%$ are illiterate [5]. Rural Development Trust General Hospital is a nonprofit 220-bed hospital in Bathalapalli, a rural village in Anantapur. The hospital belongs to a nongovernmental organization called Rural Development Trust.

2.2. Study Design. We collected epidemiological data (age and sex) and laboratory data from the hospital database of patients who attended outpatient clinics from June 1, 2011, to August 31, 2014. HIV infected patients were excluded. In patients who had more than one determination of haemoglobin during the study period, only one determination per year of age was allowed in order to avoid repeated measurements in the same patient. We used definitions of anaemia according to recommendation from the WHO (Table 1) [6]. Microcytic anaemia was defined according to cut-offs proposed by the US Centers for Disease Control and Prevention (CDC) (1-2 years: <77 fL; 3-5 years: < 79 fL; 6-11 years: $<80 \mathrm{fL}$; $12-15$ years: $<82 \mathrm{fL}$; $>15$ years: $<85 \mathrm{fL}$ ) [7].

The study was approved by the Hospital Ethical Committee. Statistical analysis was performed using Stata Statistical Software (Stata Corporation. Release 12.1 College Station, Texas, USA).

\section{Results}

The study included 73,795 determinations of haemoglobin from 69,440 patients, of which 34,399 (49.45\%) were female. The median haemoglobin concentration was $11.8 \mathrm{~g} / \mathrm{dL}$ (interquartile range (IQR), 10.2-13.3) and the median age was 25 years (IQR, 12-42). The median haemoglobin concentration was $11.3 \mathrm{~g} / \mathrm{dL}$ (IQR, 9.8-12.4) in females and $12.5 \mathrm{~g} / \mathrm{dL}$ (IQR, 10.6-14.2) in males. Haemoglobin concentrations did not change significantly during the duration of the study (Figure 1).

In Figure 2, we present the median concentration of haemoglobin and interquartile range stratified by age and gender. Children aged 6-30 months had the lowest haemoglobin concentrations. Females and males had similar haemoglobin concentrations until the onset of puberty (around age 13 years). After puberty, females had median concentrations of haemoglobin around $11.5 \mathrm{~g} / \mathrm{dL}$, whereas males had a rapid increase in haemoglobin concentrations reaching a plateau of about $14 \mathrm{~g} / \mathrm{dL}$ at age 20 years and experienced a progressive decline after age 40 years.

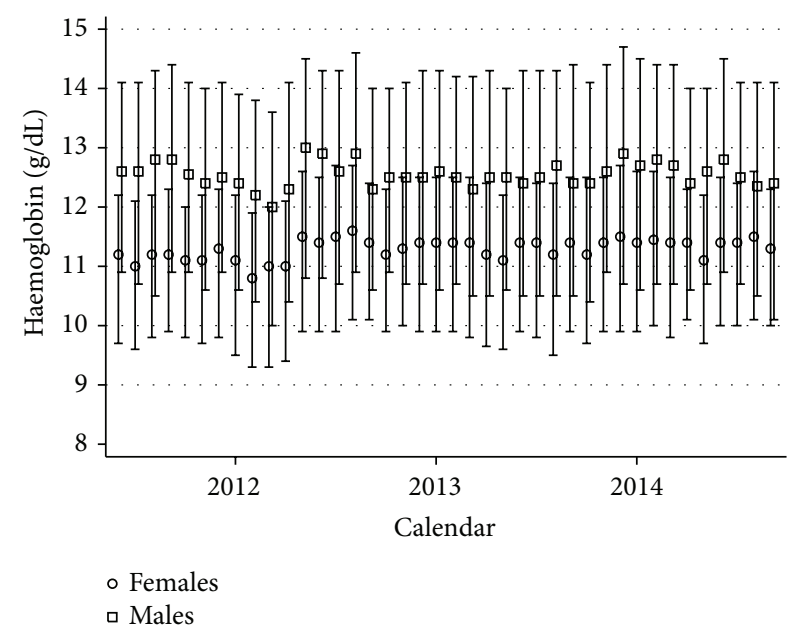

FIgURE 1: Median and interquartile range of haemoglobin concentration stratified by gender and calendar month.

The prevalence of mild, moderate, and severe anaemia is presented in Figure 3. The highest prevalence of mild and moderate anaemia was seen in children $<10$ years. The highest prevalence of moderate anaemia was seen in children aged 12 years. Both female and male children experienced a rapid improvement in the prepuberty period. After puberty, the prevalence of anaemia was constantly over $50 \%$ in females, having older women higher prevalence of moderate and severe anaemia than younger women. Males had a peak of anaemia during puberty and a progressive increase of mild, moderate, and severe anaemia with age.

The median and interquartile range of the mean corpuscular volume (MCV) in patients with anaemia is presented in Figure 4 . The vast majority of children with anaemia had low $\mathrm{MCV}$ and there were no gender differences. In adults with anaemia, males tended to have a higher MCV than women, but differences reduced with age.

The prevalence of macrocytic, normocytic, and microcytic anaemia is presented in Figure 5. In general, macrocytic anaemia was rare. While microcytic anaemia was more prevalent in children and women, the proportion of normocytic anaemia increased progressively with age in male adults and women after menopause age.

\section{Discussion}

In this retrospective observational study using routine clinical data from a large number of patients attending the outpatient clinics of a rural hospital in India, anaemia was present in the majority of children $<10$ years, women after the onset of puberty, and older adults.

The high proportion of microcytic anaemia and the fact that gender differences were only seen after the menarche period in women indicate that iron deficiency was the main cause of anaemia. In a study of children aged 12-23 months in two rural districts in India, $72 \%$ of children with anaemia had low ferritin levels [8]. Other Indian studies have also shown high prevalence of iron deficiency anaemia among 


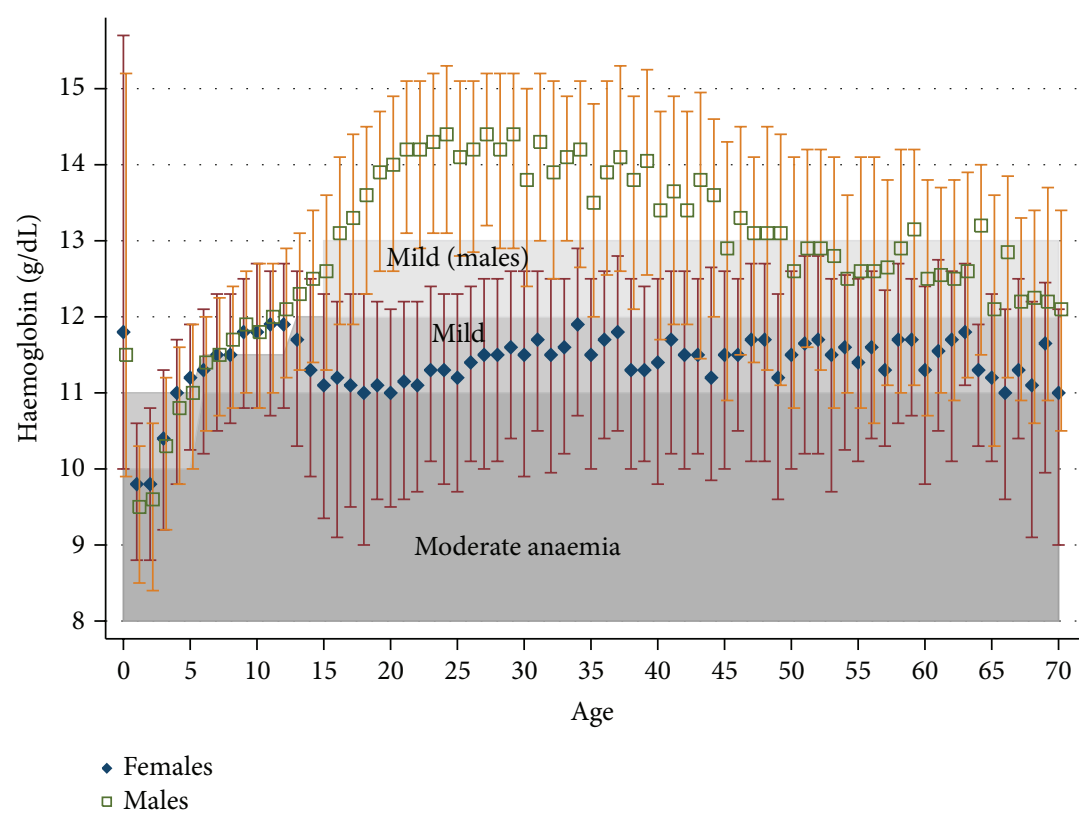

FIGURE 2: Median and interquartile range of haemoglobin concentration stratified by gender and age.

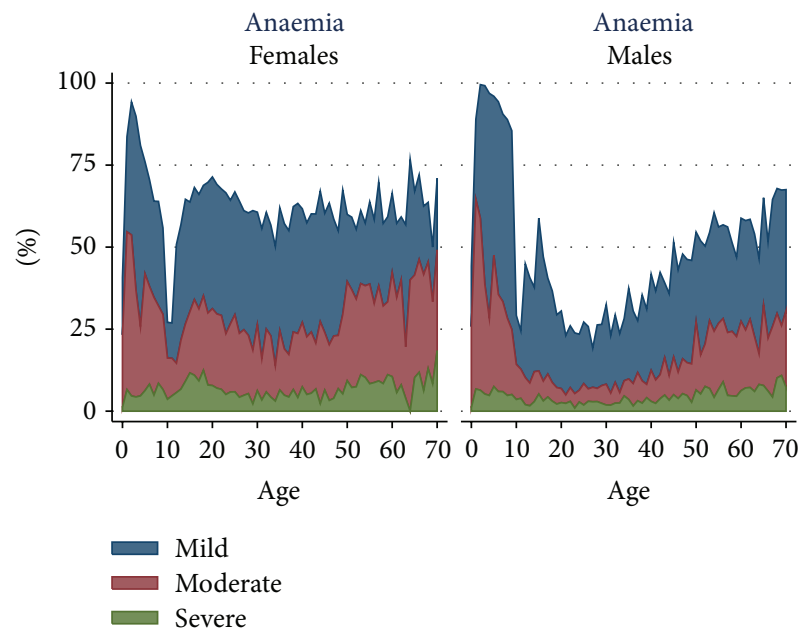

FIGURE 3: Prevalence of mild, moderate, and severe anaemia by age in males and females.

young women $[9,10]$. The high prevalence of iron deficiency anaemia among women in childbearing age has important public health implications. It is estimated that anaemia accounts for $12.8 \%$ of maternal mortality in Asia [11]. Iron requirements are greater in pregnancy, and iron deficiency is associated with maternal death, preterm delivery, and low birth-weight $[12,13]$. In India, only $28 \%$ of women consume meat, fish, or eggs on a weekly basis [4], and the iron bioavailability of the vegetarian diet is poor [10, 14]. Effective public health programmes aimed at reducing iron deficiency among young women could have a major impact in reducing maternal and infant mortality [15].

The highest prevalence of anaemia was seen in children $<10$ years, especially in those $<5$ years. In India, over
95\% of children are breastfed [4]. The WHO organization recommends introducing solid and semisolid food at the age of six months because breastfeeding does not suffice to maintain optimal growth after this age. However, at age 6-8 months only $45 \%$ of children receiving breastfeeding are given solid or semisolid food [4, 16]. Moreover, only $10 \%$ of breastfeeding children and $20 \%$ of nonbreastfeeding children aged 6-35 months eat meat, fish, or eggs [4], which are rich in haem iron with high bioavailability $[17,18]$. In the NFHS-3, only $14.6 \%$ of children aged 6-35 months consumed food rich in iron in the previous 24 hours of the survey [4]. At this age, the effect of iron deficiency on the neurological development can be not totally reversible $[3,19]$. Consequently, the Indian Government recommends iron and folic acid supplementations to younger children [20]. However, the programme implementation has been poor due to lack of logistic planning and accountability [20]. In our study, we did not observe an increase in haemoglobin concentrations during the study period suggesting that the programme has not achieved a reduction in the prevalence of anaemia in our setting. Our results are in agreement with other studies in India [21] and indicate that the iron supplementation programme for children aged $<24$ months should be better monitored.

In this study, we observed an increased prevalence of anaemia with age. Interestingly, the proportion of normocytic anaemia was highest in older adults, suggesting that other causes than iron deficiency might have contributed to the high prevalence of anaemia in this group. Recent studies have shown the poor bioavailability of vitamin B12 in the typical Indian vegetarian diet [14] and substantial prevalence of vitamin B12 deficiency in Indian patients with anaemia $[9,10,22]$. However, new studies investigating the aetiology of anaemia among older adults are needed. 


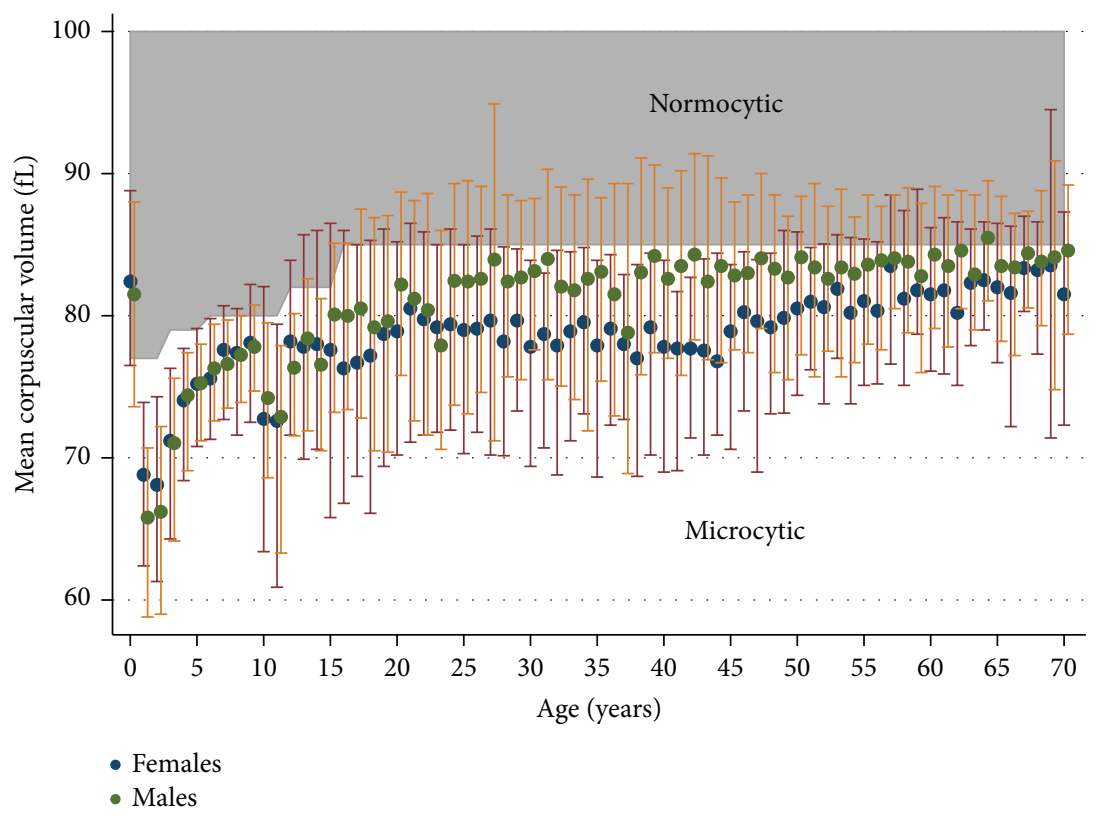

FIGURE 4: Median and interquartile range of the mean corpuscular volume in patients with anaemia stratified by gender and age.

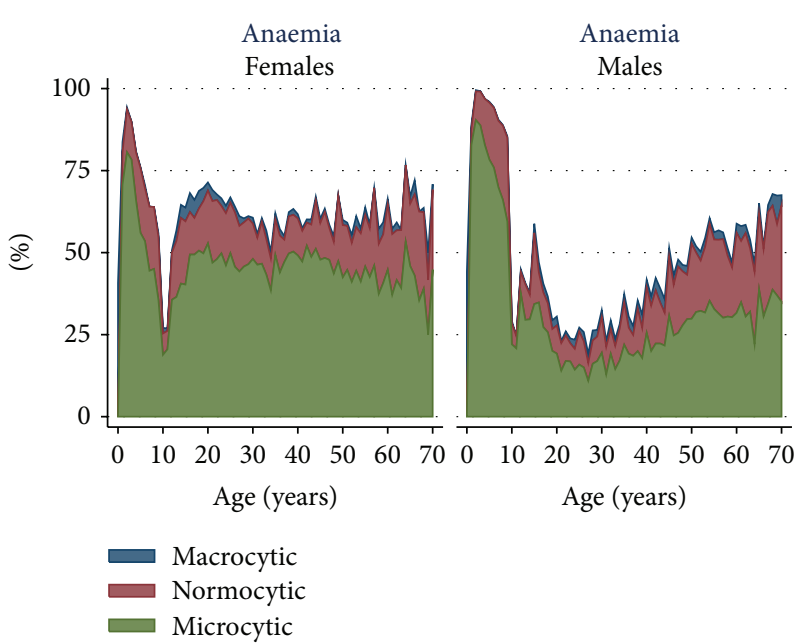

FIGURE 5: Prevalence of macrocytic, normocytic, and microcytic anaemia by age in males and females.

The study has some limitations. We used data from patients coming to the hospital to assess the prevalence of anaemia in the population. This might have led to an overestimation of anaemia in our setting. However, we excluded patients admitted to the hospital, and the prevalence of anaemia was similar to the ones reported in Andhra Pradesh in the NFHS-3 (70.8\% in children 6-59 months; $62.9 \%$ in females $15-49$ years; $23.3 \%$ in males $15-49$ years) [4].

\section{Conclusions}

In our rural setting, most patients attending out-patient clinics had anaemia. The highest prevalence of anaemia was seen in children $<10$ years followed by women and older adults. The vast majority of anaemia cases were microcytic, suggesting that iron deficiency was the main cause of anaemia. However, the prevalence of normocytic anaemia increased with age, so further studies are needed to clarify the cause of anaemia among older adults. The results of this study can be used by public health programmes to design target interventions aimed at reducing the huge burden of anaemia in India.

\section{Conflict of Interests}

The authors declare that they have no competing interests.

\section{References}

[1] WHO, UNICEF, and UNU, Iron Deficiency Anaemia: Assessment, Prevention and Control, A Guide for Programme Managers, WHO, UNICEF, UNU, Geneva, Switzerland, 2001, http:// www.who.int/nutrition/publications/micronutrients/anaemia iron_deficiency/WHO_NHD_01.3/en/index.html.

[2] M. B. Zimmermann and R. F. Hurrell, "Nutritional iron deficiency," The Lancet, vol. 370, pp. 511-520, 2007.

[3] R. D. Baker, F. R. Greer, and Committee on Nutrition American Academy of Pediatrics, "Diagnosis and prevention of iron deficiency and iron-deficiency anemia in infants and young children (0-3 years of age)," Pediatrics, vol. 126, pp. 1040-1050, 2010.

[4] F. Arnold, S. Parasuraman, P. Arokiasamy, and M. Kothari, "Nutrition in India," in National Family Health Survey (NFHS-3) India 2005-06, 2009, http://www.rchiips.org/nfhs/nutrition report_for_website_18sep09.pdf.

[5] Office of The Registrar General \& Census Commissioner, Census of India, 2011. 
[6] WHO, Haemoglobin Concentrations for the Diagnosis of Anaemia and Assessment of Severity, WHO, Geneva, Switzerland, 2011, http://www.who.int/vmnis/indicators/haemoglobin/en/.

[7] "Recommendations to prevent and control iron deficiency in the United States. Centers for Disease Control and Prevention," MMWR Recommendations and Reports, vol. 47, pp. 1-29, 1998.

[8] S.-R. Pasricha, J. Black, S. Muthayya et al., "Determinants of anemia among young children in rural India," Pediatrics, vol. 126, no. 1, pp. el40-e149, 2010.

[9] K. C. Menon, S. A. Skeaff, C. D. Thomson et al., "Concurrent micronutrient deficiencies are prevalent in nonpregnant rural and tribal women from central India," Nutrition, vol. 27 , no. 4 , pp. 496-502, 2011.

[10] P. Thankachan, S. Muthayya, T. Walczyk, A. V. Kurpad, and R. F. Hurrell, "An analysis of the etiology of anemia and iron deficiency in young women of low socioeconomic status in Bangalore, India," Food and Nutrition Bulletin, vol. 28, no. 3, pp. 328-336, 2007.

[11] K. S. Khan, D. Wojdyla, L. Say, A. M. Gülmezoglu, and P. F. van Look, "WHO analysis of causes of maternal death: a systematic review," The Lancet, vol. 367, no. 9516, pp. 1066-1074, 2006.

[12] K. Kalaivani, "Prevalence \& consequences of anaemia in pregnancy," Indian Journal of Medical Research, vol. 130, no. 5, pp. 627-633, 2009.

[13] L. H. Allen, "Anemia and iron deficiency: effects on pregnancy outcome," The American Journal of Clinical Nutrition, vol. 71, no. 5, pp. 1280s-1284s, 2000.

[14] K. Shridhar, P. K. Dhillon, L. Bowen et al., "Nutritional profile of Indian vegetarian diets-the Indian Migration Study (IMS)," Nutrition Journal, vol. 13, article 55, 2014.

[15] Z. A. Bhutta, J. K. Das, R. Bahl et al., "Can available interventions end preventable deaths in mothers, newborn babies, and stillbirths, and at what cost?" The Lancet, vol. 384, no. 9940, pp. 347-370, 2014.

[16] C. J. Chantry, C. R. Howard, and P. Auinger, "Full breastfeeding duration and risk for iron deficiency in U.S. infants," Breastfeeding Medicine, vol. 2, no. 2, pp. 63-73, 2007.

[17] M. B. Zimmermann, N. Chaouki, and R. F. Hurrell, "Iron deficiency due to consumption of a habitual diet low in bioavailable iron: a longitudinal cohort study in Moroccan children," The American Journal of Clinical Nutrition, vol. 81, no. 1, pp. 115-121, 2005.

[18] R. Hurrell, "How to ensure adequate iron absorption from ironfortified food," Nutrition Reviews, vol. 60, supplement 7, pp. S7S15, 2002.

[19] S. More, V. B. Shivkumar, N. Gangane, and S. Shende, "Effects of iron deficiency on cognitive function in school going adolescent females in rural area of central India," Anemia, vol. 2013, Article ID 819136, 5 pages, 2013.

[20] P. V. Kotecha, "Nutritional anemia in young children with focus on Asia and India," Indian Journal of Community Medicine, vol. 36, no. 1, pp. 8-16, 2011.

[21] R. K. Singh and S. Patra, "Extent of anaemia among preschool children in EAG States, India: a challenge to policy makers," Anemia, vol. 2014, Article ID 868752, 9 pages, 2014.

[22] A. Bhardwaj, D. Kumar, S. K. Raina, P. Bansal, S. Bhushan, and V. Chander, "Rapid assessment for coexistence of vitamin B12 and iron deficiency anemia among adolescent males and females in northern himalayan state of India," Anemia, vol. 2013, Article ID 959605, 5 pages, 2013. 


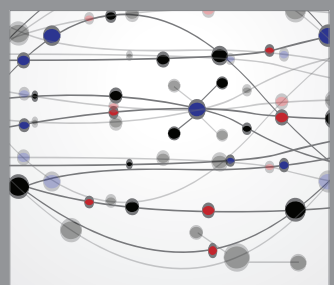

The Scientific World Journal
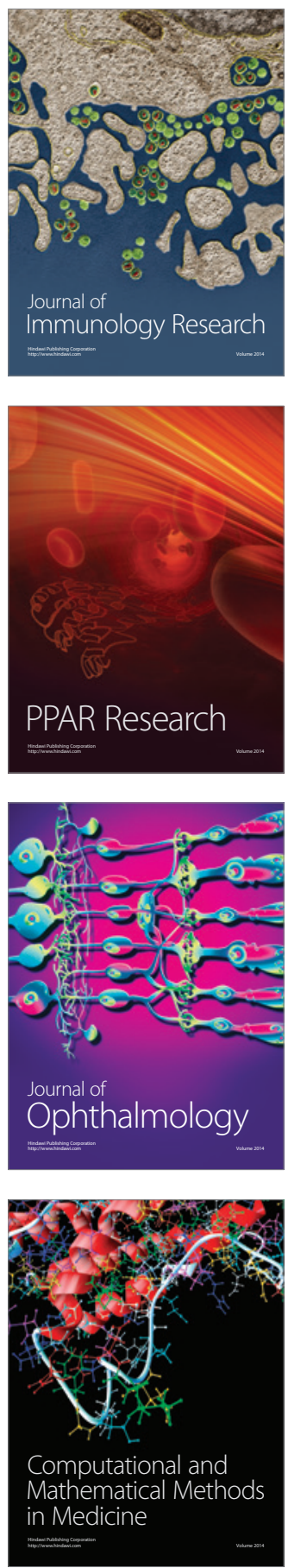

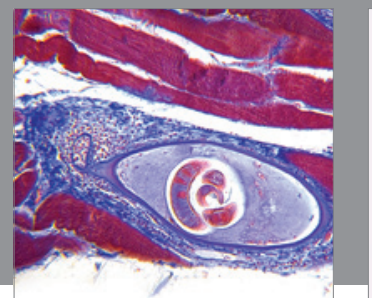

Gastroenterology

Research and Practice
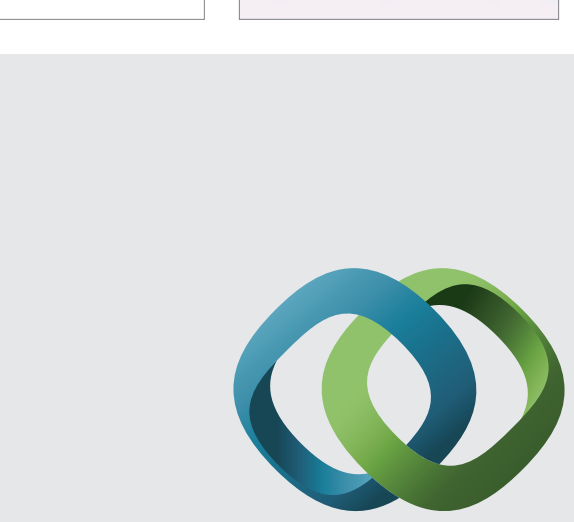

\section{Hindawi}

Submit your manuscripts at

http://www.hindawi.com
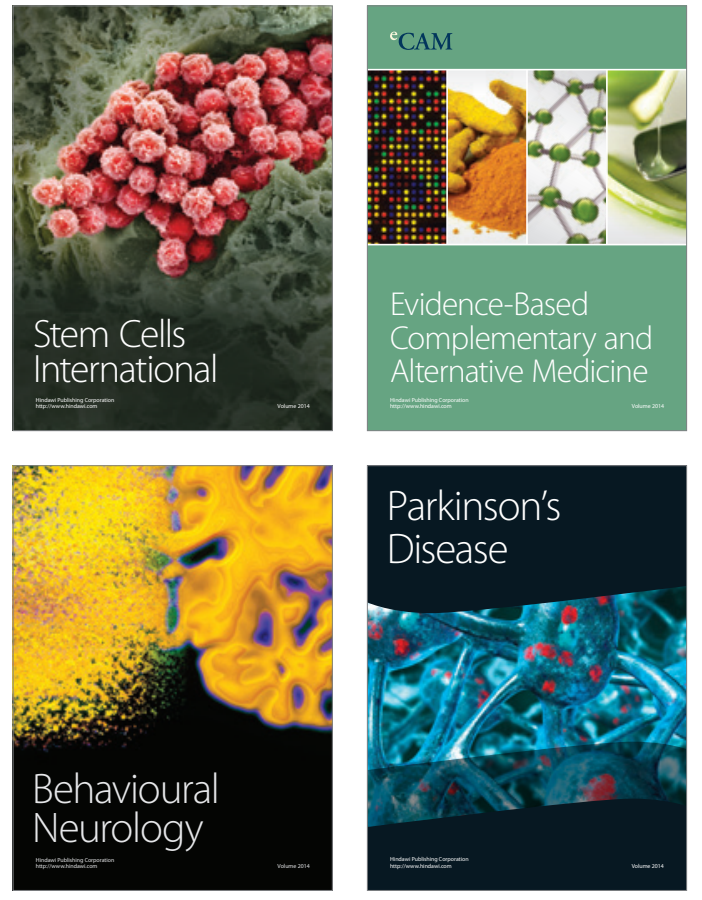
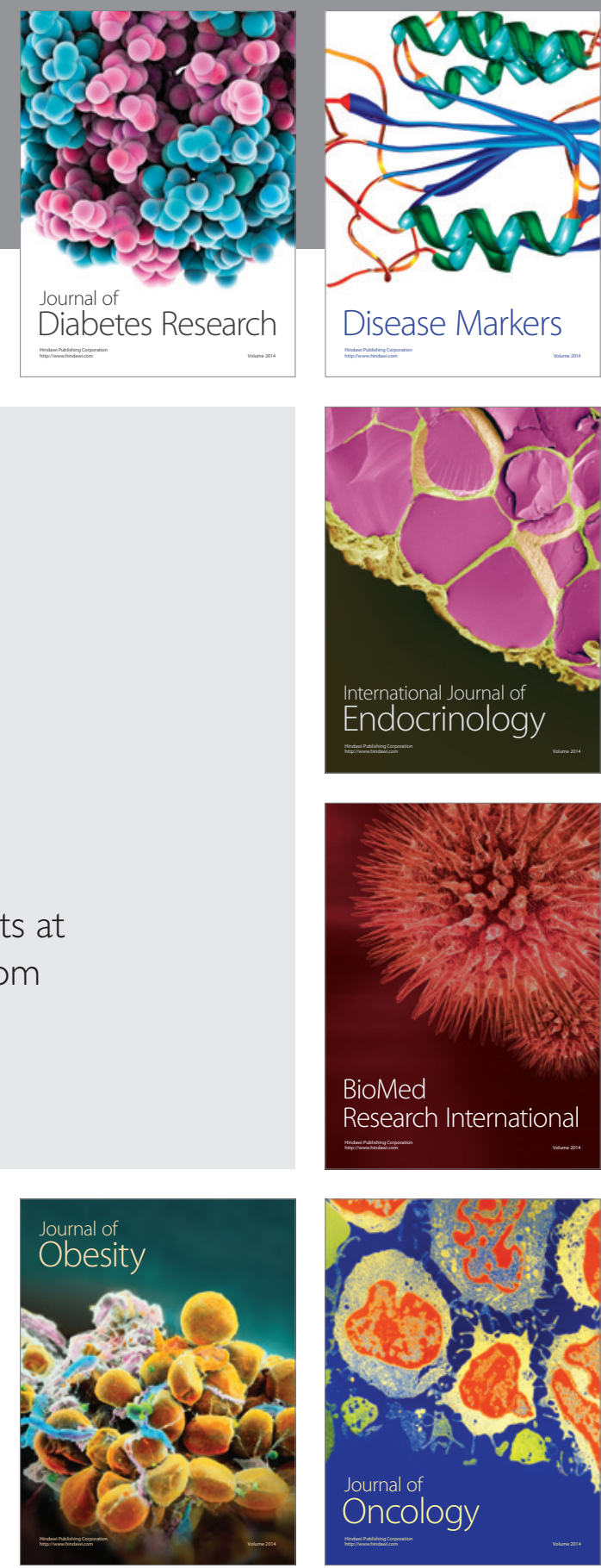

Disease Markers
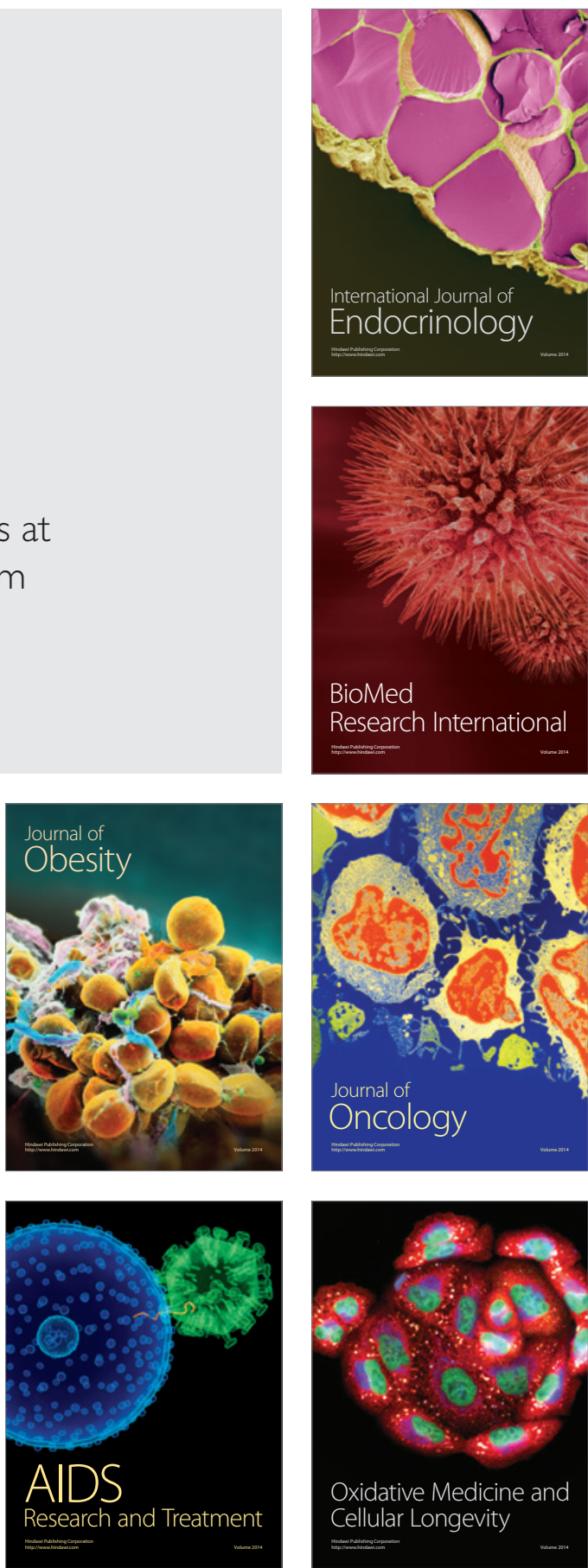